\title{
Characteristics of Human-Wildlife Conflicts in Kenya: Examples of Tsavo and Maasai Mara Regions
}

\author{
Joseph M. Mukeka ${ }^{1,2}$, Joseph O. Ogutu ${ }^{3}$, Erustus Kanga ${ }^{4} \&$ Eivin Røskaft $^{2}$ \\ ${ }^{1}$ Kenya Wildlife Service, PO Box 40241-00100 Nairobi, KENYA \\ ${ }^{2}$ Department of Biology, NTNU Gløshaugen, 7491 Trondheim, NORWAY \\ ${ }^{3}$ University of Hohenheim, GERMANY \\ ${ }^{4}$ Ministry of Tourism and Wildlife, KENYA \\ Correspondence: Joseph M. Mukeka, Kenya Wildlife Service, PO Box 40241-00100 Nairobi, KENYA. Tel: \\ 254-713-124-271. E-mail Jmukeka@kws.go.ke; mukekajoe@yahoo.com
}

Received: August 10, 2018

doi:10.5539/enrr.v8n3p148
Accepted: August 22, 2018

Online Published: September 26, 2018

\begin{abstract}
Human-wildlife conflict (HWC) is a widespread and persistent challenge to conservation. However, relatively few studies have thus far examined long-term monitoring data to quantify how the type, and severity of HWC varies across species, seasons, years and ecosystems. Here, we examine human-wildlife conflicts in Tsavo and Maasai Mara, two premier wildlife conservation areas in Kenya. Using Kenya Wildlife Service (KWS) data (2001-2016), we show that both the type and severity of conflicts vary among species such that the African elephant (Loxodonta africana), is the leading conflict species in both the Tsavo $(64.3 \%, \mathrm{n}=30664)$ and Mara $(47.0 \%, \mathrm{n}=12487)$ ecosystems. The next four most notorious conflict animals, in decreasing order, are nonhuman primates (Tsavo $11.4 \%, \mathrm{n}=3502$; Mara 11.8\%, $\mathrm{n}=1473$ ), African buffalo (Syncerus caffer, Tsavo 5.5\%, $\mathrm{n}=1676$; Mara 11.3\%, $\mathrm{n}=1410$ ), lion (Panthera leo, Tsavo 3.6\%, $\mathrm{n}=1107$; Mara 3.3\%, $\mathrm{n}=416$ ) and spotted hyena (Crocuta crocuta, Tsavo $2.4 \%, n=744$; Mara 5.8\%, $n=729)$. We group the observed conflict incidences $(n=43,151)$ into four major conflict types, including crop raiding, the most common conflict type, followed by human and livestock attacks and property damage. The severity of conflicts also varies markedly seasonally and inter-annually. Crop raiding peaks in May-July, during and at the end of the wet season when crops are maturing but is lowest in November during the late dry season and beginning of the early rains. Attacks on humans and livestock increased more than other conflict types in both Tsavo (from 2001) and Mara (from 2013). Relatively fewer people in Mara $(7.2 \%, \mathrm{n}=901$ ) than in Tsavo $(38.2 \%, \mathrm{n}=11714)$ felt threatened by wildlife, suggesting that the Maasai people are more tolerant of wildlife. Minimizing HWC is tightly linked to successfully resolving the broader conservation challenges, including enhancing ecosystem connectivity, community engagement and conservation benefits to communities.
\end{abstract}

Keywords: Human-wildlife conflicts; crop raiding; human and livestock attacks; African elephant; Tsavo and Mara ecosystems

\section{Introduction}

Wildlife often interacts with humans in different ways, however, when such interactions adversely affect or are perceived to affect the lives and livelihoods of people, then conflicts occur (Woodroffe, Thirgood, \& Rabinowitz, 2005). These negative interactions result in human-wildlife conflicts (HWC), the most common of which include: crop raiding, livestock depredation, and attacks on humans (Thouless, 1994; Woodroffe et al., 2005). Conflicts are caused by different wildlife species and occur at different intensities in different countries or parts of the same country. The African (Loxodonta africana) and Asian (Elephas maximus) elephants are key conflict animals and are involved in crop raiding and attacks on humans in these two continents (Gadd, 2005; Sitati, Walpole, Smith, \& Leader-Williams, 2003; Sarker \& Røskaft, 2014). Carnivores such as lions (Panthera leo), tigers (Panthera tigris), brown bears (Ursus arctos) and wolves (Canis lupus) often attack, and injure or kill people and livestock in many countries (Kolowski \& Holekamp, 2006, Woodroffe et al., 2005; Patterson, Kasiki, Selempo, \& Kays, 2004; Löe \& Røskaft, 2004).

The main factors driving human-wildlife conflicts include human population increase, changing land use, habitat loss, degradation and fragmentation, high livestock population density, low abundance and restricted distribution 
of wild prey, high wildlife population density, and climatic factors. Further, stochastic events such as fires and increasing interest in ecotourism and access to nature reserves also contribute to increased HWC (Distefano, 2005). These factors contribute to human-wildlife conflicts differentially in different regions of the world. For instance, in Kenya, human-elephant conflicts (HEC) are attributed to increasing human population and changes in land use (Hoare, 1999; Thouless, 1994), that has increased the interphase between people and wildlife. Human-dominated areas are more likely to be settled by people who practice agriculture, a major pull factor for elephants as a source of alternative succulent and nutritious forage (Røskaft et al., 2014).

\subsection{Human-Wildlife Conflicts in Kenya}

Kenya, like many other countries, is experiencing fast human population growth and the associated demand for more space for agriculture, human settlements, and other developments. Human population increase is accompanied with progressive habitat fragmentation and demand for space as people seek alternative livelihoods. Nevertheless, tourism is an important foreign exchange earner in Kenya (Kenya Government, 2005) and is based mainly on wildlife watching. As a result, wildlife conservation is given a high priority by the Kenyan Government. The Kenya Wildlife Service (KWS), created in 1989, has the aim of overseeing wildlife conservation in all protected and non-protected areas in Kenya, including wildlife parks, reserves, sanctuaries, and community conservancies.

Wildlife in Kenya faces many threats including poaching, habitat loss, competition for water and food with livestock and human-wildlife conflicts (HWC). KWS has been collecting data on HWC since the early 1990s for some of the areas under its jurisdiction, such as the Tsavo and Maasai Mara (Mara) regions. These two regions support most of the wildlife in Kenya (as described in details below), including the largest terrestrial mammal in the world (Ogutu et al., 2016), the African elephant, as well as some of the largest felid species, such as the lion (Panthera leo) and leopard (Panthera pardus).

Here, we use HWC monitoring data collected by KWS during 2001-2016 for both Tsavo and Mara to analyze variation in human-wildlife conflicts across species, seasons, years and regions. Specifically, we examine and compare HWC patterns for 19 wildlife species in these two important transboundary conservation ecosystems in Kenya. Our analysis differs from previous studies in these regions that have mostly concentrated on single species (e.g., Smith \& Kasiki, 2000; Sitati et al., 2003; Kaelo, 2007, Kanga et al., 2012; Mijele et al., 2013) by seeking to understand HWC patterns over the two regions during 2001-2016. HWC analyses involving multiple species monitored over long time frames are scarce because of the dearth of reliable long-term monitoring data. Kanga et al., (2012) used 12 years' (1997-2008) data from KWS to study hippopotamus (Hippopotamus amphibius) conflicts in Kenya and found a peak in June-August during crop harvest. Patterson et al., (2004) used data for four years to study livestock depredation in Tsavo and found that lions and spotted hyenas (Crocuta crocuta) killed most cattle, while cheetah (Acinonyx jubatus) killed only sheep and goats. In the Mara, over $50 \%$ of livestock attacks during one year of study were attributed to the spotted hyena (Kolowski \& Holekamp, 2006). Sitati et al., (2003) examined human-elephant conflicts (HEC) in the Mara and noted that crop raiding by elephants could be predicted from the area of cultivated land. Habitat fragmentation due to cultivation and increasing human settlements have also been identified as major drivers of HECs in the Maasai Mara Wildlife Conservancies (Kaelo, 2007; Røskaft et al., 2014). Besides, these studies are based on a single region or ecosystem, and none of them have attempted to understand the patterns of HWC between two important wildlife areas in Kenya. In this study, we examined interspecific and temporal variation in HWC in the two premier conservation regions of Kenya.

Our main objective was to analyze reported incidences of human-wildlife conflicts in the Tsavo and Mara regions, identify and characterize the conflicts caused by wildlife species and the variation across seasons, years and between the two study regions. We test the following six hypotheses:

H1: Human-elephant conflicts are more likely to occur where there are high elephant densities, close to protected areas and in areas with high human population densities. Furthermore, there is likely to be more HEC in landscapes in which agriculture is the dominant land use than in landscapes where traditional pastoralism is the predominant land use. Because of the high elephant population and the fact that the major land use outside the Tsavo National Parks is agriculture, we therefore, expect relatively more conflicts with elephants in Tsavo than in Mara. Human-elephant conflicts can be expected to be more intense in landscapes whenever these land uses are practiced.

H2: Elephant is the leading animal species in terms of crop raiding, as well as attacks on humans. Among the other large herbivores, we expect buffalo (Syncerus caffer) and hippopotamus to have frequent conflicts with humans, because they occur in relatively large numbers in the Tsavo and Mara regions and have been shown to 
frequently cause conflicts with humans (Woodroffe et al., 2005); Dunham, Ghiurghi, Cumbi, \& Urbano, 2010; Kanga et al., 2012).

H3: Among large carnivores, we hypothesize that lions will have the highest levels of reported cases of attacks on both humans and livestock. Other large carnivores such as spotted hyenas and leopards will also occasionally have conflicts with humans while cheetah and African wild dogs (Lyacaon pictus) only rarely attack humans or their livestock.

H4: We also postulate that many nonhuman primates will be involved in conflicts related to crop raiding. Baboons (Papio spp) and vervet monkeys (Cercopithecus spp.) are adapted to living at the edges of protected areas and raid farms when wild fruits are scarce.

H5: We expect more HWC to occur during the dry than the wet season when food and water are plenty. During the dry season, surface drinking water sources are fewer and wildlife move and congregate around a few permanent water sources outside of protected areas where people and their livestock are found.

H6: We expect to find fewer people in the Mara feeling threatened than in the Tsavo during HWC encounters. This is because the Mara is predominantly inhabited by the Maasai people who have a long history of co-existence with, and tolerance of, wildlife because of their traditional nomadic and pastoral lifestyles (Guggisberg, 1975; Okello, 2005; Conroy, 2013). Further, we expect to find more human fatalities during conflicts involving attacks on humans, particularly by mega-herbivores and the big cats.

\section{Study area}

\subsection{Tsavo Region}

The Tsavo ecosystem covers a total area of about $66,500 \mathrm{~km}^{2}$ and lies between longitudes $37^{\circ} 7^{\prime} \mathrm{E}-39^{\circ} 59^{\prime} \mathrm{E}$ and latitudes $0^{\circ} 58^{\prime} \mathrm{S}-4^{\circ} 22^{\prime} \mathrm{S}$ to the south of Kenya. Rainfall is bimodal but erratic, with the short rains occurring in November - December and the long rains in March- May (Van Wijngaarden, 1985). Two major rivers, the Galana and the Tsavo, pass through this extensive area. It harbors the highest number of elephants (about 13000, Ngene et al., 2017) in a contiguous land mass in Kenya. The Tsavo Ecosystem consists of two of the largest National Parks (Tsavo East: 11,747 km $\mathrm{km}^{2}$ and Tsavo West: $9065 \mathrm{~km}^{2}$ ) in Kenya plus Chyullu National Park (736 $\mathrm{km}^{2}$ ), an important water catchment. South Kitui National Reserve $\left(1133 \mathrm{~km}^{2}\right)$ is situated to the north of Tsavo East NP. The Taita Ranches, sandwiched between Tsavo West and East National Parks, is an important wildlife dispersal area and is home to the Taita people. The Taita Hills found here are densely populated owing to high rainfall and intensive agriculture (Van Wijngaarden, 1985; Figure 1). The regions adjacent to the protected areas serve as important seasonal wildlife dispersal areas.

The fauna in Tsavo consist of large herbivores, including the African elephant, African buffalo, hippopotamus, giraffe (Giraffa camelopardalis), Burchell's zebra (Equus quagga), eland (Taurotragus oryx), waterbuck (Kobus ellipsiprymnus), Coke's hartebeest (Alcelaphus buselaphus cokii), Grant's gazelle (Gazella granti), impala (Aepyceros melampus), lesser kudu (Tragelaphus imberbis), gerenuk (Litocranius walleri), warthog (Phacochoerus africanus), fringe-eared oryx (Oryx gazella callotis) and black rhino (Diceros bicornis). A wide array of large carnivores are found in the region, including the lion, cheetah, leopard, spotted hyena and the African wild dog. The population numbers of these species are monitored by KWS through tri-annual aerial surveys (once every three years) and annual ground animal censuses. For instance, between 2014 and 2017, elephant abundance increased by $4.9 \%$ while about 8600 buffaloes were counted in 2017 (Ngene et al., 2017). Long-term monitoring of elephants in the Tsavo region indicates continuous elephant population growth from 9447 (1999) through 9284 (2002), 11742 (2005), 11733 (2008), 12573 (2011), 11217 (2014) to 12866 (2017) individuals (Ngene et al., 2017). The major land use types include agriculture, which is both practiced in smalland large-scale farms that rely on either rainfall or irrigation. Closely related to this is livestock keeping either in small or large-scale farms, wildlife conservation in ranches adjacent to the two Tsavos, intensive infrastructure development, and settlements in towns such as Voi (Ngene et al., 2017). The human population has also been increasing at a similar rate as the rest of Kenya in the areas around Tsavo, especially in the Taita Taveta County $(1999, \mathrm{n}=469,244 ; 2009, \mathrm{n}=720,352)$ (https://www.knbs.or.ke). In 1999, about 2.7 million people lived in and adjacent to the Tsavo region (https://www.knbs.or.ke). This population increased to about 4.5 million people in 2009 (https://www.knbs.or.ke), translating to a population growth rate of about $4.0 \%$ per annum.

\subsection{Maasai Mara region}

The Mara region $\left(18,500 \mathrm{~km}^{2}\right)$ is found within Narok County between longitudes $34^{\circ} 34^{\prime} \mathrm{E}-36^{\circ} 26^{\prime} \mathrm{E}$ and latitudes $0^{\circ} 24^{\prime} \mathrm{S}-2^{\circ} 6^{\prime} \mathrm{S}$ to the southwestern part of Kenya, bordering Tanzania. The famous Maasai Mara National Reserve (MMNR) $\left(1510 \mathrm{~km}^{2}\right)$ to the south-west of Narok County adjoins the Serengeti National Park (SNP) in 
Tanzania to form the Greater Mara-Serengeti Ecosystem (GMSE). The Mara River, which originates from the Mau Forest ranges slithers through Narok County and the MMNR into SNP. Like the Tsavo Ecosystem, the Mara also harbours a large migratory population of wildlife. In earlier years, wildlife in the MMNR used to roam over the entire extent of Narok County up to the Mau ranges. However, recently this has changed drastically as the communal ranches that made this possible have been subdivided into individual holdings and fenced, cultivated or settled (Lamprey \& Reid, 2004) thereby greatly impeding animal movements within the Narok county. We use the term Mara here to refer to the area covered by the MMNR and extending outwards to cover the entire Narok County (Figure 1).

The fauna of the Mara is similar to that of the Tsavo except for wildebeest (Connochaetes taurinus), Burchell's zebra and Thomson's gazelle (Gazella thomsonii) are found in very large numbers compared to Tsavo. Like for Tsavo, KWS continuously monitors wildlife in the Mara and, based on the latest census in 2017, elephants numbered 2493 and buffaloes 9466 . These figures exclude about $450 \mathrm{~km}^{2}$ overlapping area traditionally counted in the Tanzanian side but not covered in the 2017 survey. The Mara region has experienced a variable (due to cross-border movements) although increasing elephant population since 1999 (1577 individuals) to 2493 individuals in 2017, and these numbers have always been above 1500 except for a low of 820 elephants in 2003 and a high of 3051 elephants in 2010 (KWS, Unpublished data). Pastoralism is the predominant form of land use in the Mara and sheep, goats and cattle are the most commonly herded species. In 2017, KWS estimated 350,000 shoats (sheep and goats) and 800,000 cattle (Mwiu et al., 2017, unpublished report). Human immigration into this area has led to the conversion of large areas into large-scale wheat and maize farms. Wildlife conservancies are found adjacent to the MMNR, while to the northern part of the County (Mau), forest conservation is a major form of land use. Human population size in Narok County was about 470,000 in 1999 and increased to about 720,000 in 2009 (https://www.knbs.or.ke). This translates to an average human population growth rate of about $3.5 \%$ per annum and, therefore, Narok will likely have an estimated human population size of about 1,000,000 by 2019 .

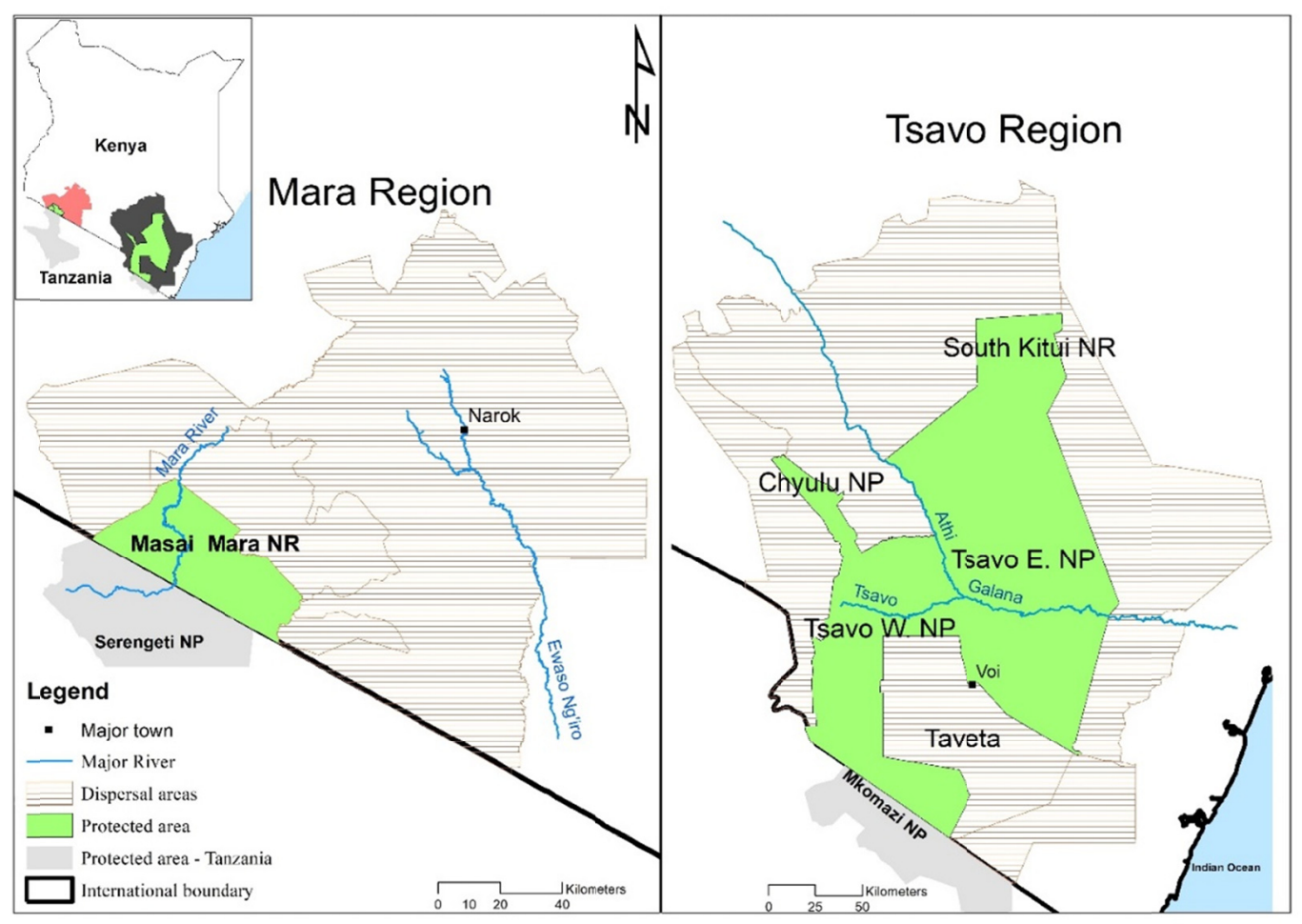

Figure 1. Map showing the Mara and Tsavo study regions in Kenya (top left corner) with surrounding dispersal areas (shaded) where human-wildlife interactions are reported. Notice the location of Taveta in the Tsavo region sandwiched between the two sections of the protected area 


\section{Methods}

\subsection{Human-Wildlife Conflict Database}

KWS established an elaborate radio network covering the whole of Kenya and its headquarters in Langata, Nairobi. Every event or incident observed by KWS field personnel, or reported to KWS by communities, conservation Non-Governmental Organizations (NGOs) and governmental agencies are relayed as radio messages through the network. As a result, KWS has been able to record numerous HWC incidences since 1990. These datasets assist KWS to appropriately respond to reports concerning HWC and act as evidence for compensation claims relating to HWC fatalities and injuries. The HWC variables reported and recorded include the date (day, month and year) of occurrence; conflict types (human death, i.e., at least one person is killed during the animal attack; human injury, i.e., at least one person is physically injured during the animal attack; human threat, i.e., at least one person felt threatened by the encounter, however, no person was injured or killed). Other variables included obstruction (wildlife obstructing school going children, vehicles, or herders); crop damage (wildlife invade farms and damage crops), and property damage (water pipes, grain stores or other property damage); livestock killed or injured; species involved (i.e., species responsible for the conflict). Mostly, one species is involved in the conflict, however, at times multiple species are involved, and sometimes the conflict species is not identified.

Based on these variables, we identified four main human-wildlife conflict types; 1) attack on humans, 2) livestock attack, 3) crop raiding and 4) property damage. Attacks on humans refer to those conflicts where a wild animal is involved in an encounter with humans, and the incident is captured in the database as human death, human injury, a threat to humans, or obstruction to school-going children or general public insecurity. Livestock attacks include incidences where livestock are killed or injured and are captured in the database as livestock depredation. Crop raiding refers to incidents where crops are either destroyed or eaten by wildlife when farms are invaded or raided. Property damage denotes incidents including damage to property such as water pipes, grain stores, and houses. The last form of conflicts is referred to as "others" and includes any other reported human-wildlife incident involving one or more than one wildlife species and incidents such as automobile accidents involving wildlife.

In some cases, we pooled together several species commonly involved in conflicts in one group. Thus, the term antelope is used to group together Kirk's dik-dik (Madoqua kirkii, $\mathrm{n}=4$ ), common duikers (Sylvicapra grimmia, $\mathrm{n}=1)$, hartebeest (Alcelaphus buselaphus, $\mathrm{n}=1)$, impala $(\mathrm{n}=77)$ bushbuck $(\mathrm{n}=21)$, lesser kudu $(\mathrm{n}=2)$, reedbuck (Redunca fulvorufula, $\mathrm{n}=3$ ), Thomson's gazelle $(\mathrm{n}=10)$, Grant's gazelle (Gazella granti, $\mathrm{n}=39$ ), wildebeest $(\mathrm{n}=95)$ or when term "antelope" was used as an umbrella conflict "species" $(\mathrm{n}=135)$ in the data. Small carnivores such as the serval cat (Leptailurus serval, $\mathrm{n}=17$ ), caracal (Caracal caracal, $\mathrm{n}=4$ ), jackal (Canis Spp., $\mathrm{n}=4$ ), mongoose (family herpestidae, $\mathrm{n}=7$ ), honey badger (mellivora capensis, $\mathrm{n}=19$ ) and civets (family Viverridae, $\mathrm{n}=1$ ) are also pooled into one group. Furthermore, primates mean baboons (Papio spp., $\mathrm{n}=$ 4328) and monkeys (Cercopithecus spp., $\mathrm{n}=647$ ) (all nonhuman primates), while bush pigs (Potamochoerus larvatus, $\mathrm{n}=50$ ), warthogs (Phacochoerus africanus, $\mathrm{n}=52$ ) and wild pigs (Sus scrofa, $\mathrm{n}=74$ ) are grouped as pigs. The last species type, "others" pools together records for which no species was indicated $(\mathrm{n}=152)$, plus conflict incidents involving birds (eagles, vultures (accipitrids) and guinea fowls (numidids), $\mathrm{n}=30$ ), bees (Apis mellifera scutellata, $\mathrm{n}=4$ ), porcupine (Hystrix cristata, $\mathrm{n}=9$ ), squirrel (sciurids, $\mathrm{n}=3$ ), scorpions (bothrirurids, $\mathrm{n}$ $=1$ ), as well as mixed conflict instances ( 19 wildlife species and one group labeled "others" (Table 1).

We also added another variable to the database called conflict outcome to denote the severity of conflicts involving humans based on a scale of 0 to $3 ; 0=$ nothing happened to humans, $1=$ humans felt threatened, $2=$ humans were injured, and 3 = humans were killed. We examine whether the conflicts resulted in any one of these four outcomes.

We use the term livestock to refer to all types of domesticated animals such as cattle, sheep, goats, donkeys, camels, dogs and poultry. Livestock attacks are grouped into three outcome categories, $0=$ nothing happened to livestock, 1 = livestock were injured, and 2 = livestock were killed.

We associate each conflict with the month in which it occurred to enable seasonal analysis. It is important to note that, although the total area of the Tsavo region is comparatively larger than that of the Mara, we compare relative frequencies of conflict cases which are independent of area and not the absolute human conflict numbers between the two regions.

Statistical analyses were done using SPSS, version 24.0 (IBM Corp. Release 2016. NY, USA). Since our data were count data, we used descriptive statistics as well as cross tabulations to compare relative frequencies between the two conservation regions. Most statistical tests were non-parametric Chi-square goodness of fit tests while few were cumulative frequency bar charts. Statistical significance is assessed at alpha $=0.05$. 


\section{Results}

\subsection{The Relative Contribution of Species to Conflict by Region}

A total of 45,151 cases of human-wildlife conflicts were reported between 2001 and 2016 for Tsavo and Mara combined. Tsavo had a total of 30,664 conflict cases compared to 12,487 cases for the Mara. This translates to an average of 1,900 human-wildlife conflict incidences per year for the Tsavo and 780 incidents for the Mara.

Most of the reported cases of conflict involved the African elephant for both the Tsavo (64.3\%) and Mara (47.0\%). However, the percentage of conflict incidences involving elephants was significantly higher for Tsavo than the Mara (Table 1, $\mathrm{P}=0.001$ ). Primates were the second most common cause of conflicts and their relative contributions to the total conflict incidents in Tsavo (11.4\%), and Mara (11.8\%) did not differ between the two regions (Table 1). Buffalo was the third most frequent conflict animal in both regions but was almost twice as likely to cause conflicts in the Mara (11.3\%) as in Tsavo (5.5\%, Table 1). The hippopotamus $(2.6 \%)$ and zebra $(2.5 \%)$ were the seventh and eighth most common causes of conflicts, respectively. However, while hippo conflict incidences were more common in Tsavo than in the Mara, the converse was the case for zebra (Table 1).

Among the carnivore species, lions had the highest but non-significant number of reported cases (3.5\%) followed by the spotted hyena (3.4\%) and the leopard (2.8\%, Table 1$)$. The cheetah and the wild dog ranked $16^{\text {th }}$ and scored low overall $(0.3 \%)$ and together with small carnivores $(0.1 \%)$ made negligible contributions to the conflict incidences (Table 1). Carnivores made a minor contribution to the conflicts relative to the large herbivores. Conflicts involving reptiles were due to pythons as well as unidentified snakes and ranked ninth $(1.6 \%)$ and tenth $(1.5 \%)$, respectively. Moreover, the crocodile often considered likely to cause conflicts, was ranked behind snakes at the $13^{\text {th }}$ position $(0.5 \%$; Table 1$)$. However, the relative frequencies for all these animals differed significantly between the two regions (Table 1).

The antelopes $(0.9 \%)$ had somewhat many reported cases in Mara $(2.50 \%)$. Waterbuck $(0.10 \%, \mathrm{n}=64)$ and giraffe $(0.10 \%, \mathrm{n}=26)$ were only very rarely reported as conflict species (Table 1$)$. The "others" group was also an insignificant source of conflicts and was ranked $13^{\text {th }}(0.5 \%, \mathrm{n}=222$; Table 1$)$. Overall, our results indicate significant differences between the two regions $\left(\chi^{2}=5451.2, \mathrm{df}=19, \mathrm{P}<0.001\right)$.

Table 1. The common English and scientific names of the human-wildlife conflicts species, ordered by the number of cases of conflicts involving each species in Tsavo and Mara, and chi-squared goodness of fit tests for the null hypothesis that the percentage contribution of each species to the total conflicts differs between the two regions $(\mathrm{n}=$ number of reported cases, $\%$ is $n$ expressed as a percentage of the total number of cases for the region)

\begin{tabular}{|c|c|c|c|c|c|c|c|c|c|}
\hline \multirow[t]{2}{*}{ No } & \multirow[t]{2}{*}{ Common English name of species } & \multirow[t]{2}{*}{ Scientific name of species } & \multicolumn{2}{|c|}{ Tsavo } & \multicolumn{2}{|c|}{ Mara } & \multicolumn{3}{|c|}{ Pearson Chi-square test } \\
\hline & & & $n$ & $\%$ & $n$ & $\%$ & $\mathrm{X}^{2}$ & df & $\mathrm{P}<0.05$ \\
\hline 1 & Elephant & Loxodonta africana & 19719 & 64.3 & 5875 & 47.0 & 1094.8 & 1 & 0.001 \\
\hline 2 & Primates & Cercopithecidae family & 3502 & 11.4 & 1473 & 11.8 & 1.2 & 1 & 0.267 \\
\hline 3 & Buffalo & Syncerus caffer & 1676 & 5.5 & 1410 & 11.3 & 453.6 & 1 & 0.001 \\
\hline 4 & Lion & Panthera leo & 1107 & 3.6 & 416 & 3.3 & 2.0 & 1 & 0.155 \\
\hline 5 & Spotted hyena & Crocuta crocuta & 744 & 2.4 & 729 & 5.8 & 313.3 & 1 & 0.001 \\
\hline 6 & Leopard & Panthera pardus & 526 & 1.7 & 698 & 5.6 & 483.3 & 1 & 0.001 \\
\hline 7 & Hippopotamus & Hippopotamus amphibius & 1032 & 4.4 & 71 & 0.6 & 278.7 & 1 & 0.001 \\
\hline 8 & Zebra & Equus quagga & 64 & 0.2 & 1013 & 8.1 & 2277.9 & 1 & 0.001 \\
\hline 9 & Python & Python sebae & 695 & 2.3 & 0 & 0.0 & 287.6 & 1 & 0.001 \\
\hline 10 & Snake & Serpentes suborder & 596 & 1.9 & 70 & 0.6 & 111.7 & 1 & 0.001 \\
\hline 11 & Antelope (assorted) & Bovidae family & 73 & 0.2 & 315 & 2.5 & 519.8 & 1 & 0.001 \\
\hline 12 & Eland & Taurotragus oryx & 275 & 0.9 & 37 & 0.3 & 44.6 & 1 & 0.001 \\
\hline 13 & Others $* 1$ & & 100 & 0.3 & 122 & 1.0 & 73.5 & 1 & 0.001 \\
\hline 13 & Crocodile $*^{1}$ & Crocodylus niloticus & 199 & 0.6 & 14 & 0.1 & 52.1 & 1 & 0.001 \\
\hline 15 & Pigs (assorted) ${ }^{* 3}$ & Suidae family & 86 & 0.3 & 90 & 0.7 & 42.4 & 1 & 0.001 \\
\hline 16 & Cheetah $*^{2}$ & Acinonyx jubatus & 130 & 0.4 & 13 & 0.1 & 27.5 & 1 & 0.001 \\
\hline 16 & Wild dog $*^{2}$ & Lycaon pictus & 35 & 0.1 & 104 & 0.8 & 142.8 & 1 & 0.001 \\
\hline 18 & Waterbuck $*^{3}$ & Kobus ellipsiprymnus & 38 & 0.1 & 26 & 0.2 & 4.3 & 1 & 0.039 \\
\hline 18 & Small carnivores $*^{3}$ & $* 4$ & 52 & 0.2 & 0 & 0.0 & 21.2 & 1 & 0.001 \\
\hline \multirow[t]{2}{*}{18} & Giraffe $*^{3}$ & Giraffa camelopardalis & 15 & 0.0 & 11 & 0.1 & 2.3 & 1 & 0.133 \\
\hline & Total & & 30664 & 100 & 12487 & 100 & 5451.2 & 19 & 0.001 \\
\hline
\end{tabular}

$*^{1-3}$ These species had an equal overall frequency contribution to HWCs $(0.5 \%, 0.3 \%$, and $0.1 \%)$ respectively.

${ }^{*}$ Families - Viverridae, Canidae, Herpestidae, Felidae, and Mustelidae 


\subsection{Frequency of Conflict Types by Species Between Tsavo and Mara}

The elephant emerged as the leading conflict animal in three out of the five conflict types, namely attacks on humans $($ Tsavo $=74.6 \%$, Mara $=64.8 \%)$, crop raiding $($ Tsavo $=65.8 \%$, Mara $=47.3 \%)$ and property damage $($ Tsavo $=90.5 \%$, Mara $=89.4 \%$ ), with Tsavo reporting a relatively higher number of cases. However, the leading species causing livestock attacks was the lion $($ Tsavo $=31.8 \%$, Mara $=16.7 \%)$ and the spotted hyena (Tsavo $=$ $23.2 \%$, Mara $=35 \%$ ). The contributions of primates to crop raiding incidences were similar for the Tsavo (20.8\%) and Mara (19.8\%). There were higher attacks on humans incidents ascribed to buffalo in the Mara $(20.9 \%)$ than in the Tsavo $(8.0 \%)$. The spotted hyena (Mara $=35 \%$, Tsavo $=23.2 \%)$ and leopard $($ Mara $=30.3 \%$, Tsavo $=14.9 \%)$ accounted for higher livestock attacks in the Mara than Tsavo. Pythons attacked humans (4.8\%) and livestock $(1.4 \%)$ only in Tsavo. Snake bite incidences were relatively higher for Tsavo $(4.3 \%, \mathrm{n}=578)$ than Mara $(1.6 \%, \mathrm{n}=62)($ Table 2$)$.

\section{Table 2. Conflict types by species}

The contribution of each of the 10 leading conflict species to the most prevalent conflict types in both Tsavo and Mara. The Chi-squared goodness of tests for the null hypothesis that each species makes a uniform contribution to all the conflict types in each region

\begin{tabular}{|c|c|c|c|c|c|c|c|c|c|c|c|c|c|c|c|}
\hline & \multirow[b]{2}{*}{ NO } & \multirow[b]{2}{*}{ Species } & \multicolumn{2}{|c|}{$\begin{array}{c}\text { Attacks on } \\
\text { humans }\end{array}$} & \multicolumn{2}{|c|}{ Crop raiding } & \multicolumn{2}{|c|}{$\begin{array}{c}\text { Livestock } \\
\text { attack }\end{array}$} & \multicolumn{2}{|c|}{$\begin{array}{l}\text { Property } \\
\text { damage }\end{array}$} & \multicolumn{2}{|c|}{ Other } & \multicolumn{3}{|c|}{ Pearson Chi-square test } \\
\hline & & & $\mathrm{n}$ & $\%$ & $\mathrm{n}$ & $\%$ & $\mathrm{n}$ & $\%$ & $\mathrm{n}$ & $\%$ & $\mathrm{n}$ & $\%$ & $\mathrm{X}^{2}$ & $\mathrm{df}$ & $\mathrm{P}<0.05$ \\
\hline \multirow{10}{*}{ 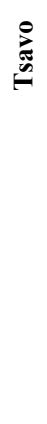 } & 1 & Elephant & 10093 & 74.6 & 9094 & 65.8 & 84 & 3.1 & 446 & 90.5 & 2 & 2.9 & 5391.8 & 4 & 0.001 \\
\hline & 2 & Primate & 182 & 1.3 & 2869 & 20.8 & 410 & 14.9 & 20 & 4.1 & 21 & 30.9 & 2634.4 & 4 & 0.001 \\
\hline & 3 & Buffalo & 1083 & 8.0 & 565 & 4.1 & 13 & 0.5 & 5 & 1.0 & 10 & 14.7 & 382.3 & 4 & 0.001 \\
\hline & 4 & Lion & 219 & 1.6 & 9 & 0.1 & 876 & 31.8 & 1 & 0.2 & 2 & 2.9 & 6971.6 & 4 & 0.001 \\
\hline & 5 & Hyena & 97 & 0.7 & 7 & 0.1 & 637 & 23.2 & 1 & 0.2 & 2 & 2.9 & 5499.9 & 4 & 0.001 \\
\hline & 6 & Leopard & 110 & 0.8 & 5 & 0.0 & 410 & 14.9 & 1 & 0.2 & 0 & 0.0 & 3142.5 & 4 & 0.001 \\
\hline & 7 & Hippo & 262 & 1.9 & 751 & 5.4 & 6 & 0.2 & 5 & 1.0 & 8 & 11.8 & 373.8 & 4 & 0.001 \\
\hline & 8 & Zebra & 10 & 0.1 & 48 & 0.3 & 0 & 0.0 & 2 & 0.4 & 4 & 5.9 & 136.3 & 4 & 0.001 \\
\hline & 9 & Python & 654 & 4.8 & 2 & 0.0 & 38 & 1.4 & 1 & 0.2 & 0 & 0.0 & 739.6 & 4 & 0.001 \\
\hline & 10 & Snake & 578 & 4.3 & 3 & 0.0 & 15 & 0.5 & 0 & 0.0 & 0 & 0.0 & 691.9 & 4 & 0.001 \\
\hline \multirow{10}{*}{$\stackrel{\pi}{\tilde{\pi}}$} & 1 & Elephant & 2193 & 64.8 & 3051 & 47.3 & 90 & 4.6 & 463 & 89.4 & 78 & 47.6 & 2227.8 & 4 & 0.001 \\
\hline & 2 & Primate & 59 & 1.7 & 1279 & 19.8 & 112 & 5.7 & 16 & 3.1 & 7 & 4.3 & 844.4 & 4 & 0.001 \\
\hline & 3 & Buffalo & 708 & 20.9 & 650 & 10.1 & 14 & 0.7 & 12 & 2.3 & 26 & 15.9 & 588.6 & 4 & 0.001 \\
\hline & 4 & Lion & 78 & 2.3 & 1 & 0.0 & 329 & 16.7 & 0 & 0.0 & 8 & 4.9 & 1345.5 & 4 & 0.001 \\
\hline & 5 & Hyena & 37 & 1.1 & 0 & 0.0 & 688 & 35.0 & 3 & 0.6 & 1 & 0.6 & 3608.9 & 4 & 0.001 \\
\hline & 6 & Leopard & 98 & 2.9 & 3 & 0.0 & 597 & 30.3 & 0 & 0.0 & 0 & 0.0 & 2746.2 & 4 & 0.001 \\
\hline & 7 & Hippo & 58 & 1.7 & 9 & 0.1 & 0 & 0.0 & 3 & 0.6 & 1 & 0.6 & 110.9 & 4 & 0.001 \\
\hline & 8 & Zebra & 5 & 0.1 & 998 & 15.5 & 0 & 0.0 & 7 & 1.4 & 3 & 1.8 & 969.6 & 4 & 0.001 \\
\hline & 9 & Python* & & & & & & & & & & & - & & \\
\hline & 10 & Snake & 62 & 1.8 & 0 & 0.0 & 6 & 0.3 & 0 & 0.0 & 2 & 1.2 & 141.2 & 4 & 0.001 \\
\hline
\end{tabular}

*Python conflict incidents were not reported in the Mara region.

\subsection{Frequency of Conflict Types in Tsavo and Mara}

Crop raiding was the leading type of conflict in both the Mara $(51.7 \%, \mathrm{n}=6455)$ and Tsavo $(45.1 \%, \mathrm{n}=13820)$ and accounted for $47 \%$ of all the reported cases in both regions. The number of attacks on humans were higher for Tsavo $(44.1 \%, \mathrm{n}=13532)$ than the Mara $(27.1 \%, \mathrm{n}=3382)$ and accounted for $39.2 \%$ of all the conflict cases for both regions combined. Livestock attack was the third most common conflict type (10.9\%), but was relatively higher for the Mara $(15.8 \%, \mathrm{n}=1968)$ than the Tsavo $(9.0 \%, \mathrm{n}=2751)$. Other conflict types were far fewer even though property damage accounted for $2.3 \%$ of the cases in both regions (Table 3 ). The overall relative frequency differed significantly between the two regions for all the conflict types $(\mathrm{P}<0.001$, Table 3$)$ when the two regions are combined. 
Table 3. The contributions of the different conflict types in Tsavo and Mara for the period 2001-2016 and the chi-squared tests of independence for the null hypothesis that each conflict type makes a similar contribution to the total in both regions

\begin{tabular}{|c|c|c|c|c|c|c|c|}
\hline \multirow[t]{2}{*}{ Conflict type } & \multicolumn{2}{|c|}{ Tsavo } & \multicolumn{2}{|c|}{ Mara } & \multicolumn{3}{|c|}{ Pearson Chi-Square test } \\
\hline & $\mathrm{n}$ & $\%$ & $\mathrm{n}$ & $\%$ & $\mathrm{X}^{2}$ & df & $\mathrm{P}<0.05$ \\
\hline Crop raiding & 13820 & 45.1 & 6455 & 51.7 & 156.3 & 1 & 0.001 \\
\hline Attack on humans & 13532 & 44.1 & 3382 & 27.1 & 1081.8 & 1 & 0.001 \\
\hline Livestock attack & 2751 & 9.0 & 1968 & 15.8 & 419.9 & 1 & 0.001 \\
\hline Property damage & 493 & 1.6 & 518 & 4.1 & 250.3 & 1 & 0.001 \\
\hline Other & 68 & 0.2 & 164 & 1.3 & 197.7 & 1 & 0.001 \\
\hline Total & 30664 & 100.0 & 12487 & 100.0 & 1555.7 & 4 & 0.001 \\
\hline
\end{tabular}

\subsection{Seasonal Variation in the Frequency of the Common Conflict Types}

The most frequent type of conflict was crop raiding and peaked in May-July when the frequencies were pooled across both regions (Figure 2). However, when considered for each region separately, crop raiding was more pronounced in March-September in Mara and January-February and May-July in Tsavo than in the rest of the year (Fig. 3). Attacks on humans were the next most frequent conflict type after crop raiding followed by livestock attacks, property damage, and others, in decreasing order. These human-wildlife conflict types were not only relatively rare but also displayed no evident seasonality in both regions (Figs 2 and 3).

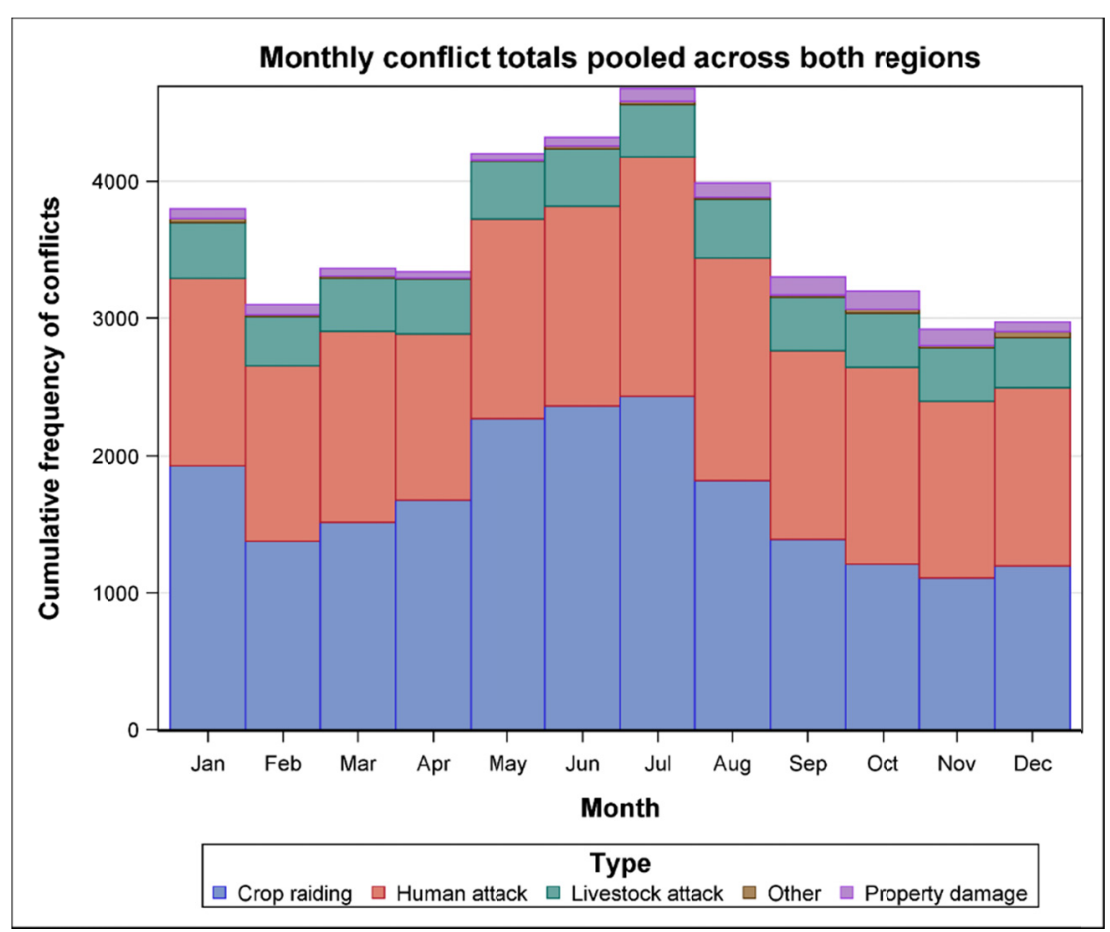

Figure 2. The distribution of the cumulative frequency of the common conflict types across months. The frequency of each conflict type has been pooled over the Tsavo and Mara regions

Crop raiding incidences in the Mara increased from March to a unimodal peak in July and then declined thereafter (Figure 3). Unlike for the Mara, Tsavo experienced a bimodal peak in crop raiding with a secondary peak in January-February and a primary peak in May-Jul (Figure 3).

\subsection{Inter-Annual Variation in the Frequency of the Common Conflict Types}

There were evident temporal trends in the major conflict types, but the trends differed between the two regions. In Tsavo, crop raiding was the most common conflict type during 2001-2007 but dropped precipitously to a low in 2010 before increasing steadily again during 2011-2016. However, the frequency of crop raiding in 2016 was still lower than the levels attained in 2001-2007. In sharp contrast to crop raiding, attacks on humans increased 
strikingly from 2001 to 2016 and surpassed crop raiding as the most common conflict type during 2009-2016 (Figure 4). Though relatively less frequent, livestock attacks also increased from 2001 to 2016, similarly to crop raiding (Figure 4). In the Mara, crop raiding and attacks on humans increased markedly from 2001 to peak in 2008-2009 and declined steadily thereafter. However, livestock attacks remained relatively stable during 2001-2013 and began increasing in 2014 (Figure 4). Conflicts related to property damage showed no apparent temporal pattern in both regions (Figure 4).

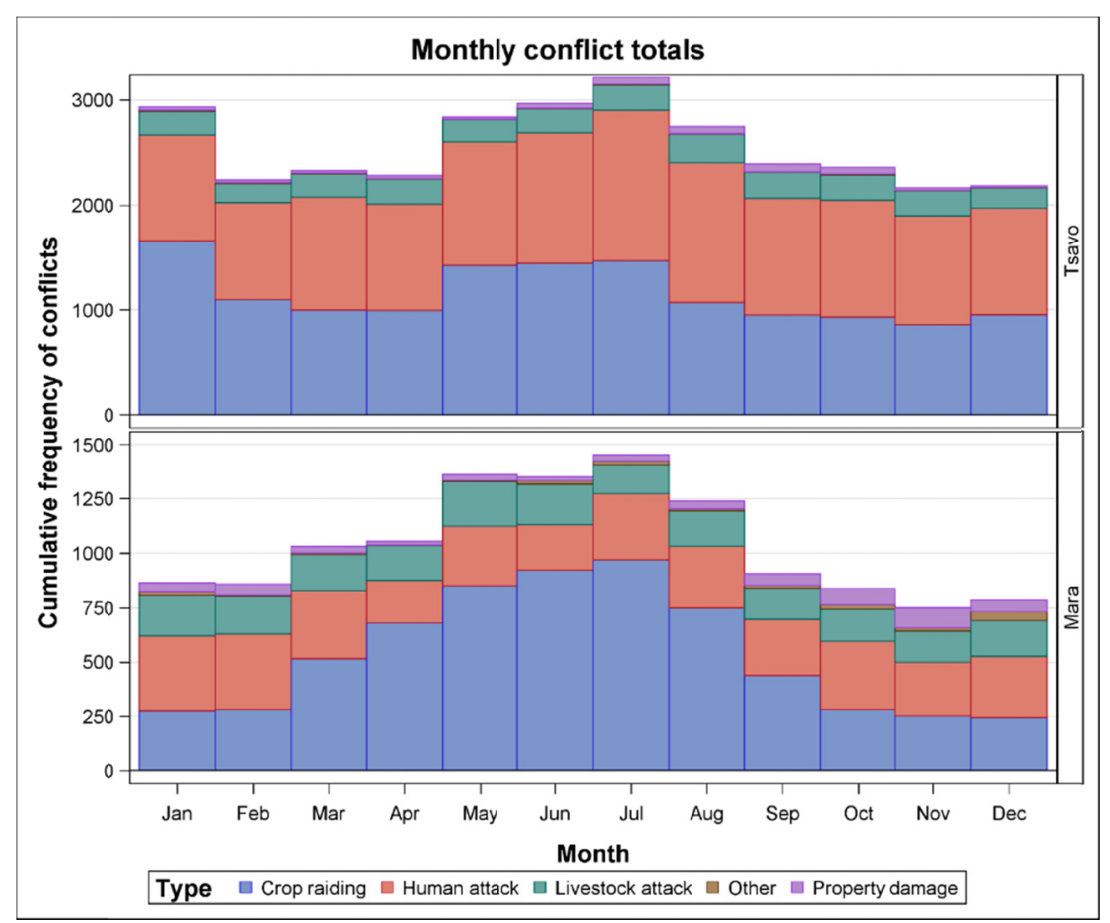

Figure 3. The distribution of the cumulative frequency of conflict types across months in Tsavo (top) and Maasai Mara (bottom) regions

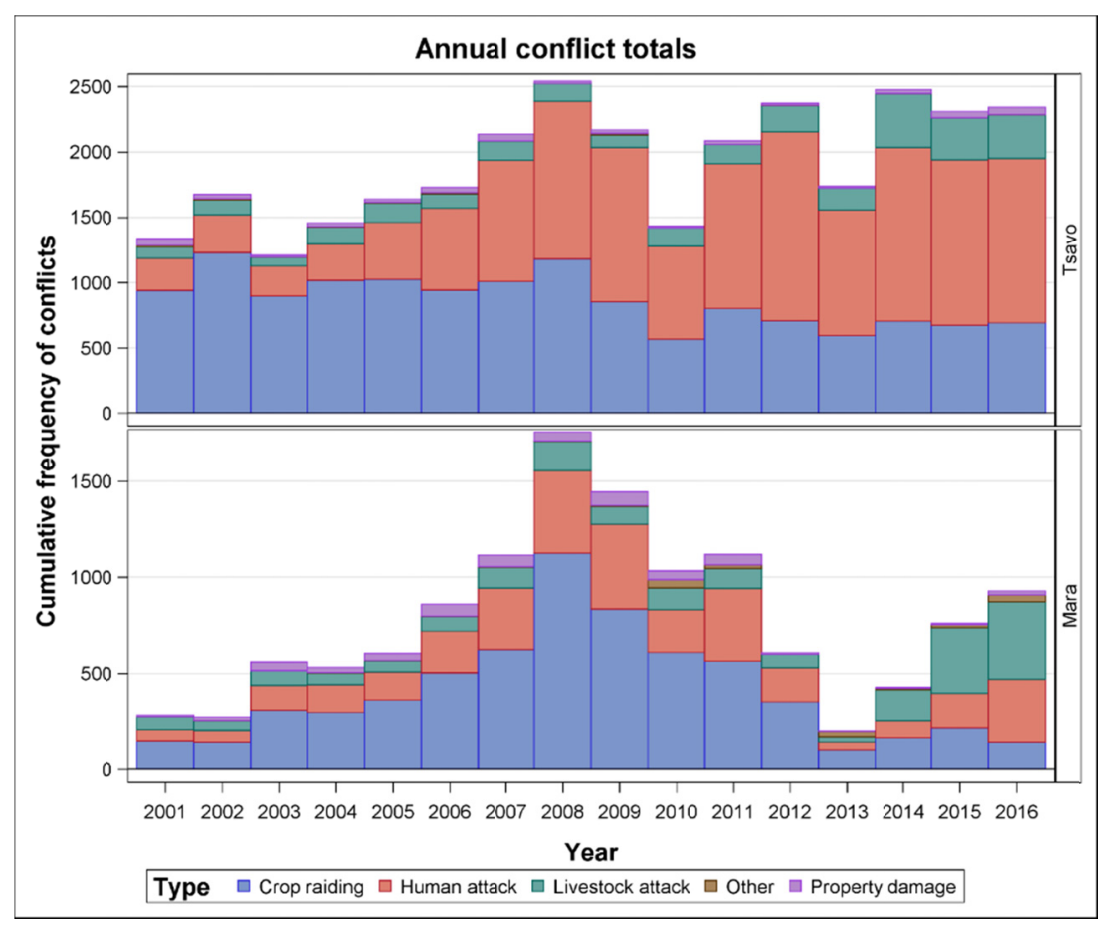

Figure 4. The inter-annual variation in the cumulative frequency of the common conflict types for the Tsavo (top) and Mara (bottom) regions 


\subsection{Conflict Type Outcome Differences between Tsavo and Mara}

Here, we examine the outcomes of conflicts involving human and livestock attacks. Humans either felt threatened, were injured or killed during many conflict incidents in both the study regions (Table 4). Twice as many people were killed in Tsavo $(0.9 \%, \mathrm{n}=278)$ as in the Mara $(1.0 \%, \mathrm{n}=126)$ during 2001-2016 though the difference was not statistically significant $(\mathrm{P}=0.316)$. In contrast, more conflict incidents reported for the Mara $(89 \%, \mathrm{n}=11113)$ than for Tsavo $(56 \%, \mathrm{n}=17174)$ did not involve human injury, death or threats to people (Table 4).

Table 4. Outcomes of conflicts involving humans in the Tsavo and Mara regions

\begin{tabular}{lccccccc}
\hline \multirow{2}{*}{ Conflict outcome } & \multicolumn{2}{c}{ Tsavo } & \multicolumn{2}{c}{ Mara } & \multicolumn{2}{c}{ Pearson Chi-square test } \\
\cline { 2 - 8 } & $\mathrm{n}$ & $\%$ & $\mathrm{n}$ & $\%$ & $\mathrm{n}$ & $\mathrm{df}$ & $\mathrm{P}<0.05$ \\
\hline Nothing happened to humans & 17174 & 56.0 & 11113 & 89.0 & 4276.7 & 1 & 0.001 \\
Humans felt threatened & 11714 & 38.2 & 901 & 7.2 & 4118.1 & 1 & 0.001 \\
Humans were injured & 1498 & 4.9 & 347 & 2.8 & 96.2 & 1 & 0.001 \\
Humans were killed & 278 & 0.9 & 126 & 1.0 & 1.0 & 1 & 0.316 \\
Total & $\mathbf{3 0 6 6 4}$ & $\mathbf{1 0 0}$ & $\mathbf{1 2 4 8 7}$ & $\mathbf{1 0 0}$ & $\mathbf{4 4 8 0 . 4}$ & $\mathbf{3}$ & $\mathbf{0 . 0 0 1}$ \\
\hline
\end{tabular}

\subsection{Human Wildlife Conflict Outcomes in Tsavo and Mara}

Conflicts involving attacks on humans resulted in the highest cases of humans getting killed $(2.4 \%, n=398)$, human injuries (10.7\%), and humans feeling threatened $(74.6 \%)$. Tsavo had relatively higher frequency of incidents in which humans either felt threatened $(86.6 \%, \mathrm{n}=11712 ; 26.6 \%, \mathrm{n}=901)$ or were injured $(10.8 \%, \mathrm{n}=$ $1466 ; 10.2 \%, \mathrm{n}=344)$ but fewer incidents involving human fatalities $(2.0 \%, \mathrm{n}=272 ; 3.7 \%, \mathrm{n}=126)$ than the Mara.

During conflicts involving livestock attacks, very few cases also resulted in humans being either killed or injured. Tsavo had more cases of human injuries $(0.9 \%, \mathrm{n}=25)$ during livestock attacks than the Mara $(0.1 \%, \mathrm{n}$ =2). The Mara reported no cases of humans being killed during livestock attacks between 2001 and 2016 as opposed to Tsavo $(0.2 \%, \mathrm{n}=5)$.

Though they were the most frequently recorded conflict types, conflicts involving crop or property damage were rarely associated with human injuries. Thus, for the Tsavo region, crop damage $(0.0 \%, \mathrm{n}=6)$ was hardly associated with human injuries (See Table S5 in the appendix)

\subsection{Livestock Attack Conflict Outcomes}

Livestock attacks resulted in livestock either being killed (59.3\% of the cases) or not (35.2\%). In addition, a small proportion of livestock attacks (5.5\%) resulted in livestock being injured (Table 6). Livestock was also either injured $(0.1 \%)$ or killed $(3.4 \%)$ during conflicts classified as property damage. Some attacks on humans $(0.3 \%)$ and crop raiding $(0.1 \%)$ incidents also resulted in livestock being killed.

Livestock attacks resulted in relatively more incidents of livestock being killed in Tsavo $(81.3 \%, \mathrm{n}=2237)$ than the Mara $(28.5 \%, \mathrm{n}=561)$, while Mara $(13.1 \%, \mathrm{n}=257)$ had relatively higher incidences of livestock injuries than Tsavo $(0.1 \%, \mathrm{n}=4)$. Tsavo region also had livestock killed during property $(6.9 \%, \mathrm{n}=34)$ and human $(0.4 \%, \mathrm{n}=50)$ attacks, while similar outcomes were relatively rare for the Mara (Table S6 in the supplementary materials).

\section{Discussion}

\subsection{Prevalence of Human Elephant Conflicts in Tsavo and Mara Regions}

The results reveal that the African elephant is the leading wildlife conflict species in both Tsavo and Mara regions, but there are higher relative conflict incidences for the Tsavo than for the Mara. This supports hypotheses H1 and H2. In H1, we hypothesized that human elephant conflicts (HEC) are more likely to occur where elephant density is high, close to protected areas and where human population density is high. According to the KWS' aerial survey of 2017, there are 12866 elephants in the Tsavo region and the southern part of the Tsavo East National Park has 7.01 elephants $/ \mathrm{km}^{2}$, Taveta has 1.86 elephants $/ \mathrm{km}^{2}$, and Tsavo West National Park has 2.99 elephants $/ \mathrm{km}^{2}$ (Ngene et al., 2017). However, in Mara, a KWS' aerial survey of 2017 found a total of 2493 elephants with a density ranging from 1.73 elephants $/ \mathrm{km}^{2}$ in the protected area to 0.01 elephants $/ \mathrm{km}^{2}$ in the adjacent dispersal area (Mwiu et al., 2017, unpublished report). The Tsavo region is surrounded to the southern, south western and northern sides by the Taita 
and Kamba communities who practice agriculture in small farms adjacent to the protected areas. Further, the Kasigau corridor (important for wildlife) joins Tsavo East and Tsavo West NP through Taita area (Wildlife Works, 2013). This makes them more vulnerable to HEC conflicts due to the increasing elephant and human populations. This is unlike in the Mara where the indigenous Maasai people predominantly practice pastoralism, which is more compatible with wildlife conservation (Conroy, 2013, Okello, 2005). The trend of increasing HEC observed in the Mara region is due to the gradual sedentarization of these once nomadic pastoralists and the increasing conversion of land to large-scale wheat farming and human settlements. Nomadic pastoralism in Kenya is decreasing principally due to the scarcity of land and water (Okello, 2005) and is giving way to agro-pastoralism as a form of livelihoods for the Maasai. The elephant is the largest living terrestrial mammal and requires large amounts of food and water per day, and hence have large home ranges to obtain these resources. These movements lead to frequent conflicts between elephants and humans. This supports $\mathrm{H} 2$ which predicts that elephants should lead in crop raiding and attacking humans. Further, buffalo accounted for $7.2 \%$ and the hippopotamus for $2.6 \%$ of the reported cases of conflict. Buffalo was second to elephants in terms of attacks on humans, while hippopotamus was linked to crop raiding as earlier reported by Kanga et al. (2013). Indeed, based on these results, the elephant may be labeled as the 'most notorious' conflict species in Kenya, accounting for $80 \%$ of all conflict types and being the leading conflict species in four out of five conflict types. Persistent human-elephant conflicts pose great challenges to conservation managers as a form of land use, and the Kenyan state will likely have to shoulder greater compensation burdens for human fatalities in future. Land use entails a tradeoff between what local communities perceive to be more lucrative, which is often agriculture (Okello, 2005), and this threatens wildlife conservation by reducing conservation space.

\subsection{Occurrence and Differences in Human Carnivore Conflicts for Tsavo and Mara}

Overall, our results indicate that the lion is the leading cause of large carnivore-related conflicts. A closer examination of conflict types revealed differences between the Tsavo and the Mara regions. In the Mara, livestock attack conflicts were most likely to be caused by the spotted hyena, the leopard, and the lion. These results are consistent with those of Kolowski and Holekamp (2006) who also found livestock attacks in the Mara to be caused mainly by the spotted hyena (53\%), the leopard (32\%) and the lion $(15 \%)$. In the Tsavo region, by contrast, livestock attacks were most often caused by the lion, the spotted hyena, and the leopard. However, the lion accounted for more incidences of attacks on humans in both the Tsavo and Mara, followed by the leopard and the hyena. This accords with $\mathbf{H 3}$ which predicts that lions should have the highest reported cases of attacks on both humans and livestock while other large carnivores, such as spotted hyenas and leopards (Tweheyo et al., 2012) should less frequently cause conflict with humans. Carnivores are known to kill livestock (Patterson et al., 2004) as they experience reduced range and where their wild prey base has been reduced, and other forms of land use are being practiced. There were relatively more incidences of livestock attacks by the spotted hyena and leopard in the Mara than the Tsavo. The Mara is experiencing drastic land use changes and population increase (from births and immigration) which jeopardize the harmony that once existed between traditional pastoralism and wildlife (Lamprey \& Reid, 2004; Kolowski \& Holekamp, 2006; Schuette et al., 2013) resulting in increased HWC. It is likely that conflict incidences associated with the spotted hyena and leopard in the Mara involve primarily sheep and goats that are kept in large numbers, as they are more tolerant to droughts and can be kept in smaller land parcels than cattle. The once pastoral Maasai community has changed progressively to agro-pastoralism, thus fragmenting wildlife habitats (Okello, 2005; Conroy, 2013). Sheep and goat numbers increased in Narok County during 1977-2016 (Ogutu et al., 2016). However, this regional difference can also be attributed to differences in carnivore densities and husbandry practices (Kolowski \& Holekamp, 2006). There were rare but noteworthy wild dog conflict incidences reported for the Mara, which abuts the Serengeti National Park in Tanzania. Lyamuya et al., (2014) and Holmern et al., (2007) have recently reported livestock predation by wild dogs in Serengeti, Tanzania. It is likely that these conflicts will persist in the future in both regions. Increased livestock depredation is likely to lead to decreased tolerance of carnivores (Kolowski \& Holekamp, 2006) by local communities and therefore compromise their conservation.

\subsection{Occurrence of other HWC Including Primates, Pythons, and Snakes in Tsavo and Mara}

Our results also indicate that primates are a major cause of HWC in Kenya, second only to the elephant. Primates were mainly responsible for crop raiding and livestock attacks but rarely attacked humans. This supports hypothesis $\mathbf{H 4}$ predicting frequent conflicts related to crop raiding by baboons and monkeys. Like other wildlife, the primates, too, are faced with shrinking habitats and are often forced to co-exist with humans. This often results in baboons and monkeys becoming 'primate pests' due to their role in crop raiding (Strum, 2010; Hill, 1997) and being negatively perceived by local communities and thus becoming of conservation concern (Dickman, 2012). Python and snakes made greater contributions to HWC occurrences in Tsavo than in the Mara. This makes python and snake bites an important conflict type for humans. In Uganda, pythons have been 
reported as responsible for livestock attacks (Tweheyo et al., 2012). In Kenya, the Wildlife Conservation and Management Act 2013 recognizes that snakes can often lead to fatal or serious human injuries and therefore provides that victims be compensated, unlike the previous Act of 1989, which lacked this provision.

Other wildlife species also played key roles in the HWC conflicts in the two regions. However, giraffe caused the least number of conflicts and was ranked the last species in order of relative frequencies of conflict incidences. This shows that all other wildlife species, such as giraffe, though they only rarely come into conflicts with humans can cause conflicts. For instance, the crocodile often considered a very dangerous animal and feared by many people, accounted for few of the conflict incidences in Tsavo $(0.6 \%, \mathrm{n}=199)$ and Mara $(0.1 \%, \mathrm{n}$ $=14$ ). The few cases of crocodile conflicts in these two regions do not necessarily reflect the national threat posed to humans and livestock by crocodiles and may reflect the fact that crocodiles inhabit sections of large rivers within protected areas with low human and livestock populations. Small carnivores also had few reported incidences, although most of their conflicts, e.g., targeting poultry, may often go unreported.

\subsection{Seasonality and Inter-Annual Variation in Human-Wildlife Conflicts}

Severe droughts can lead to serious water and food shortages for wildlife and therefore increase competition for resources between humans and livestock (Kanga et al. 2013). Crop raiding, the most frequent type of conflict peaked in May - July for the two regions. May is the time of year when most crops reach maturity while June and July are the typical harvesting times for most crops grown in these regions. This implies succulent and nutritious food that is attractive to wild herbivores is abundant during these three months. This is consistent with H5 that seasonality is an important predictor of HWC and that there are fewer HWC during the wet than the dry season (Tweheyo et al., 2012) when food and water resources are scarce. Patterson et al., (2004) found that there was a higher incidence of lion depredation on livestock in Tsavo in the wet season. The extended continuous period for incidences of crop raiding in Mara (March-September) compared to Tsavo (January-February and May-July) reflect the fact that the two regions receive rains at different times but may also indicate other underlying factors not considered in this study. For instance, the Tsavo region receives bimodal rainfall with very distinctive short and long dry seasons (Van Wijngaarden, 1985). All these periods correspond to harvesting times for most crops (e.g., wheat and maize). Other conflict types were not seasonal, likely reflecting their nature and causes, e.g., attacks on humans can occur during any time of the year irrespective of season.

Human disturbance of wildlife habitats (Lamprey \& Reid, 2004; Ogutu et al., 2014) increase HWC but its effects differ from one region to another. The temporal trends in conflict incidences show that incidences of attacks on humans have been increasing in the Tsavo regions since 2001 and surpassed crop raiding, which was at its lowest in 2010. Livestock attacks in the Mara, by contrast, have been increasing since 2013. We suggest that more attacks on humans are occurring in Tsavo due to increasing human and wildlife populations in the protected and adjacent areas while increasing livestock numbers (Ogutu et al. 2011; 2016) in the Mara are responsible for increasing livestock attacks there. Furthermore, KWS has stepped up a fencing programme around the Tsavo protected areas hence keeping crop raiding elephants away from farms, but this fails to prevent the smaller-bodied carnivores from moving out.

\subsection{Conflict Type Outcomes for Tsavo and Mara}

Conflicts involving attacks on humans resulted in many incidences of people feeling threatened, injured or killed. Occasionally, people are injured or killed during livestock attacks and property damage as they try to protect their livestock from depredation or property from being damaged. In Tsavo (38.2\%), more people reported feeling threatened than in the Mara (7.2\%). That relatively fewer people felt threatened by wildlife in the Mara reflects the historically relatively more harmonious co-existence of the Maasai community with wildlife (H6). This is unlike in the Tsavo where the people living in the dispersal areas are agriculturists and are more likely to report any wildlife they encounter to the government. The Maasai people are known to tolerate wildlife unless their livestock or lives are in danger and it is not rare to find cattle grazing together with wildlife (Conroy, 2013).

We also examined the outcomes of conflicts involving livestock based on three outcome categories (nothing happened to livestock, livestock were injured or killed) for the five conflict types. The most frequent incidents of livestock being killed occurred during livestock attacks. That livestock was rarely killed or injured during other conflict types, such as property damage, shows that human-wildlife conflicts can occur in multiple dimensions. Relatively more livestock attack incidences in Tsavo (81.3\%) resulted in livestock being killed than in the Mara $(28.5 \%)$. This could be because the Maasai have morans (warriors) who aggressively protect their livestock from predators when attacked (Lyamuya et al., 2016). This underlies the problem of depredation of livestock in Tsavo and Mara regions. 


\section{Conclusions and Recommendations for Wildlife Conservation and Management}

Human-wildlife conflicts differ starkly in their types and frequencies between the Mara and Tsavo regions of Kenya. However, crop raiding is the most common type of HWC in both regions. Although the wildlife species involved in HWC also differ between the two regions, the elephant is the leading HWC species regardless of region. Non-human primates are the second most important group of wildlife species causing HWC in both regions. Elephant and primates are also the two leading groups of crop raiding wildlife species, not only in the two study regions but also elsewhere in Kenya (Strum, 1994, Graham, Notter, Adams, Lee, \& Ochieng, 2010, Conroy, 2013). Thus, a recent trend of decreasing crop raiding and increasing attacks on humans in Tsavo implicates either shifting land use or effective HEC mitigation measures. For example, KWS has recently intensified fencing efforts around Tsavo PAs to limit elephant movements (Wambua et al., Unpub Report).

Rainfall seasonality is a key driver of HWC in both the Mara and Tsavo regions. However, climate change, by reducing or making rainfall more erratic, can amplify the effect of rainfall seasonality on HWC. A marked change in rainfall seasonality can heighten HWC by aggravating competition for food and water between livestock, wildlife, and people (Reed, 2012). Unsurprisingly, crop raiding conflicts peak immediately after the wet season, when food and water become limiting.

Thus, the following alternatives for addressing human-wildlife conflicts in Kenya are envisioned:

1) HWC mitigation measures should aim to reduce the influence of rainfall seasonality on wildlife and local communities through the provision of water (to homesteads and wildlife) and other interventions that minimize resource competition. Effective strategies and methods are needed to counteract the harmful impacts of HWC on wildlife and human communities. Ideally, such methods should take account of distinctions in HWC incidence types and frequencies across regions, seasons, predominant land use types and wildlife species. Methods developed thus far to combat crop raiding by elephants and other large herbivores in Kenya include erecting fences, barriers (vegetative, moats and ditches, stone walls), and active management (scaring, translocations, problem animal control (PAC)). In contrast, approaches used for primates mostly involve active management, such as translocation, guarding farms and PAC. For carnivores, the most widely used methods in Kenya are predator-proof livestock holdings (Hill, 1997, Omondi, Bitok, \& Kagiri, 2004). The strategy adopted in particular localities vary depending on the type of HWC and the target wildlife species. However, HWC mitigation strategies are not always effective. For example, translocating a problem animal can work well in some situations, but can amount to transferring the problem in others (Dickman, 2010, Massei, Quy, Gurney, \& Cowan, 2010, White \& Ward, 2011). Technology is being increasingly used to aid HWC prevention and mitigation measures. For example, HWC prevention is being enhanced by geo-fencing in both study regions and elsewhere in Kenya by fitting elephants and lions with GPS-enabled collars to allow timely responses to problem animals. This is already producing useful data for understanding species movements in space and time, enabling timely responses to HWC incidences.

2) Fencing is one of the widely used interventions to contain HWC. Even so, the effects of fences are contested in conservation circles (Packer et al., 2013, Woodroffe, Hedges, \& Durant, 2014). Fences (electric or non-electric) need to be built and maintained (both expensive) along PA boundaries to prevent large herbivores from raiding farms, as predator-proof livestock enclosures, and to protect agricultural farms and schools. However, fences are not an effective solution to HWC for all species and are often ineffective for primates, birds, burrowing animals and other species. The future of wildlife conservation in the two study areas, as in most others, will thus most strongly depend upon the good will and support of the local communities. These can be enhanced by conservation education targeting communities living adjacent to PAs or within human-dominated pastoral systems (Gadd, 2005, Gambay, 2014, Mmassy \& Røskaft, 2014).

3) A growing threat to biodiversity conservation that is increasing HWC is spiraling human population density. If well- educated people prefer smaller households and care more for the environment (Lutz, Cuaresma, \& Sanderson, 2008), then investing in better education may help to reduce human population and hence HWC. Better conservation benefits to communities and more equitable benefit sharing schemes can encourage positive community attitudes toward and support for wildlife conservation (Kala \& Maikhuri, 2011). As tourism is a leading foreign exchange earner for Kenya escalating HWC poses serious challenges not only to wildlife conservation but also to national development. Economic benefits to local communities from ecotourism enterprises in the two study regions, and the rest of Kenya, have encouraged communities to set community-based wildlife conservancies that have greatly expanded the space available for wildlife conservation in recent years. This has also reduced HWC by reducing contacts between people, 
livestock and wildlife as landowners voluntarily vacate their land parcels for wildlife conservancies in return for land rents and resettle elsewhere (Bedelian \& Ogutu 2017; Ogutu et al. 2017).

4) The prevention and mitigation of HWC in Kenya and hence the success of conservation is complicated by the interplay of several other factors, including land use change, privatization of land ownership, land subdivision and declining traditional pastoralism, which was more compatible with wildlife conservation (Lamprey \& Reid, 2004). The Kenyan state needs to seriously consider reviewing the national policy on land use and spatial planning, and giving greater priority to protecting wildlife habitats, including dispersal and migratory corridors to reduce HWC and promote wildlife conservation. This will reduce habitat fragmentation and maintain habitat connectivity for migratory and wide-ranging wildlife species. Close monitoring and effective law enforcement are needed to ensure that the intended goals are achieved.

5) Combating HWC places a huge burden on wildlife managers, conservationists, and communities and requires substantial human and financial resources. The Kenyan state and the international community would do well to work together to address this growing challenge as well as establishing a functional mechanism for funding compensation schemes for HWC-related losses. A similar approach is also needed in the provision of anti-venom drugs for snake bites, which are common in the Tsavo region. This will encourage and improve local communities' good will and support for conservation.

6) Because the Tsavo and Mara are cross-border ecosystems shared by Kenya and Tanzania, HWC prevention and mitigation strategies should ideally involve transboundary collaboration between the two states. HWC represents a serious and mounting challenge to contemporary conservation. Securing the future of wildlife and their ecosystems in the context of the expanding human population, changing land use developments, climate change and other factors calls for enhancing investments in conservation to improve HWC prevention and mitigation strategies.

\section{Acknowledgements}

We thank KWS for allowing us to use the conflict data. KWS Tsavo and Mara Research Centers have been instrumental in keeping some of the longest HWC datasets in Kenya. The field researchers at the two research stations assisted with compiling the conflict data. JO was supported by a grant from the German Research Foundation (DFG, Grant No. OG 83/1-1). This project has received funding from the European Union's Horizon 2020 research and innovation programme under Grant Agreement No. 641918 (AfricanBioServices).

\section{References}

Bedelian, C., \& Ogutu, J. O. (2017). Trade-offs for climate-resilient pastoral livelihoods in wildlife conservancies in the Mara ecosystem, Kenya. Pastoralism, 7(1), 10. https://doi.org/10.1186/s13570-017-0085-1

Conroy, A. (2013). Maasai agriculture and land use change. Livestock, Environment and Development Initiative (LEAD) of the FAO Electronic Newsletter, 5(2), 1.

Dickman, A. J. (2010). Complexities of conflict: the importance of considering social factors for effectively resolving human-wildlife conflict. Animal Conservation, 13(5), 458-466. https://doi.org/10.1111/j.1469 $-1795.2010 .00368 . x$

Gadd, M. E. (2005). Conservation outside of parks: attitudes of local people in Laikipia, Kenya. Environmental Conservation, 32(01), 50-63. https://doi.org/10.1111/j.1469-1795.2010.00368.x

Dickman, A. J. (2012). From Cheetahs to Chimpanzees: A Comparative Review of the Drivers of Human-Carnivore Conflict and Human-Primate Conflict. Folia Primatologica, 83(3-6), 377-387. https://doi.org/10.1159/000339812

Distefano, E. (2005). Human-Wildlife Conflict worldwide: collection of case studies, analysis of management strategies and good practices. Food and Agricultural Organization of the United Nations (FAO), Sustainable Agriculture and Rural Development Initiative (SARDI), Rome, Italy. Retrieved from https://www.tnrf.org/files/E-INFO-Human-Wildlife_Conflict_worldwide_case_studies_by_Elisa_Distefano _no_date.pdf

Dunham, K. M., Ghiurghi, A., Cumbi, R., \& Urbano, F. (2010). Human-wildlife conflict in Mozambique: a national perspective, with emphasis on wildlife attacks on humans. Oryx, 44(2), 185-193. https://doi.org/10. 1017/S003060530999086X

Gadd, M. E. (2005). Conservation outside of parks: attitudes of local people in Laikipia, Kenya. Environmental Conservation, 32(01), 50-63. https://doi.org/10.1017/S0376892905001918 
Gambay, J. G. (2014). Conservation Outside Protected Areas: The Perspectives of Local Community Leaders in Southern Ngorongoro Conservation Area, Karatu District Tanzania (Master's Thesis). Institutt for biologi.

Graham, M. D., Notter, B., Adams, W. M., Lee, P. C., \& Ochieng, T. N. (2010). Patterns of crop-raiding by elephants, Loxodonta africana, in Laikipia, Kenya, and the management of human-elephant conflict. Systematics and Biodiversity, 8(4), 435-445. https://doi.org/10.1080/14772000.2010.533716

Guggisberg, C. A. W. (1975). Wild cats of the world. David \& Charles, New York.

Hill, C. M. (1997). Crop-raiding by wild vertebrates: The farmer's perspective in an agricultural community in western Uganda. International Journal of Pest Management, 43(1), 77-84. https://doi.org/10.1080/0967 08797229022

Hoare, R. E. (1999). Determinants of human-elephant conflict in a land-use mosaic. Journal of Applied Ecology, 36(5), 689-700. https://doi.org/10.1046/j.1365-2664.1999.00437.x

Holmern, T., Nyahongo, J., \& Røskaft, E. (2007). Livestock loss caused by predators outside the Serengeti National Park, Tanzania. Biological Conservation, 135(4), 518-526. https://doi.org/10.1016/j.biocon. 2006.10.049

Kaelo, D. (2007). Human-elephant conflict in pastoral areas north of Massai Mara National Reserve, Kenya. MSc thesis. (Moi Univ, Eldoret, Kenya).

Kala, C. P., \& Maikhuri, R. K. (2011). Mitigating people-park conflicts on resource use through ecotourism: A case of the Nanda Devi Biosphere Reserve, Indian Himalaya. Journal of Mountain Science, 8(1), 87-95. https://doi.org/10.1007/s11629-011-1010-5

Kanga, E. M., Ogutu, J. O., Piepho, H.-P., \& Olff, H. (2012). Human-hippo conflicts in Kenya during 1997-2008: vulnerability of a megaherbivore to anthropogenic land use changes. Journal of Land Use Science, 7(4), 395-406. https://doi.org/10.1080/1747423X.2011.590235

Kanga, E. M., Ogutu, J. O., Piepho, H.-P., \& Olff, H. (2013). Hippopotamus and livestock grazing: influences on riparian vegetation and facilitation of other herbivores in the Mara Region of Kenya. Landscape and Ecological Engineering, 9(1), 47-58. https://doi.org/10.1007/s11355-011-0175-y

Kenya Government. (2005). Kenya Interim Poverty Reduction Strategy Paper 2005. Retrieved from http://www.imf.org /external/pubs/ft/scr/2005/cr0511.pdf. Accessed 09.10.2005.

Kolowski, J. M., \& Holekamp, K. E. (2006). Spatial, temporal, and physical characteristics of livestock depredations by large carnivores along a Kenyan reserve border. Biological Conservation, 128(4), 529-541. https://doi.org/10.1016/j.biocon.2005.10.021

Lamprey, R. H., \& Reid, R. S. (2004). Expansion of human settlement in Kenya's Maasai Mara: what future for pastoralism and wildlife? Journal of Biogeography, 31(6), 997-1032. https://doi.org/10.1111/j.1365 -2699.2004.01062.x

Löe, J., \& Røskaft, E. (2004). Large carnivores and human safety: a review. AMBIO: A Journal of the Human Environment, 33(6), 283-288. https://doi.org/10.1579/0044-7447-33.6.283

Lutz, W., Cuaresma, J. C., \& Sanderson, W. (2008). The demography of educational attainment and economic growth. Population, 25(29), 15-19. https://doi.org/10.1126/science.1151753

Lyamuya, R. D., Masenga, E. H., Fyumagwa, R. D., Mwita, M. N., \& Røskaft, E. (2016). Pastoralist herding efficiency in dealing with carnivore-livestock conflicts in the eastern Serengeti, Tanzania. International Journal of Biodiversity Science, Ecosystem Services \& Management, 12(3), 202-211. https://doi.org/10. 1080/21513732.2016.1163735

Lyamuya, R. D., Masenga, E. H., Fyumagwa, R. D., \& Røskaft, E. (2014). Human-carnivore conflict over livestock in the eastern part of the Serengeti ecosystem, with a particular focus on the African wild dog Lycaon pictus. Oryx, 48(3), 378-384. doi:10.1017/S0030605312001706

Massei, G., Quy, R. J., Gurney, J., \& Cowan, D. P. (2010). Can translocations be used to mitigate human-wildlife conflicts? Wildlife Research, 37(5), 428-439. https://doi.org/10.1071/WR08179

Mijele, D., Obanda, V., Omondi, P., Soriguer, R. C., Gakuya, F., Otiende, M., ... Alasaad, S. (2013). Spatio-temporal distribution of injured elephants in Masai Mara and the putative negative and positive roles of the local community. PloS One, 8(7), e71179. https://doi.org/10.1371/journal.pone.0071179 
Mmassy, E. C., \& Røskaft, E. (2014). Factors affecting local ecological knowledge and perceived threat to the kori bustard (Ardeotis kori struthiunculus) in the Serengeti Ecosystem, Northern Tanzania. International Journal of Biodiversity and Conservation, 6(6), 459-467. https://doi.org/10.5897/IJBC2014.0719

Ngene, S., Lala, F., Nzisa, M., Kimitei, K., Mukeka, J., Kiambi, S., ... Khayale, C. (2017). Aerial total count of elephants, buffalo and giraffe in the tsavo-mkomazi ecosystem (February 2017).

Ogutu, J. O., Owen-Smith, N., Piepho, H. P., \& Said, M. Y. (2011). Continuing wildlife population declines and range contraction in the Mara region of Kenya during 1977-2009. Journal of Zoology, 285(2), 99-109. https://doi.org/10.1111/j.1469-7998.2011.00818.x

Ogutu, J. O., Piepho, H.-P., Said, M. Y., Ojwang, G. O., Njino, L. W., Kifugo, S. C., \& Wargute, P. W. (2016). Extreme wildlife declines and concurrent increase in livestock numbers in Kenya: What are the causes? PloS One, 11(9), e0163249. https://doi.org/10.1080/09709274.2011.11906389

Ogutu, J. O., Kuloba, B., Piepho, H. P., \& Kanga, E. (2017). Wildlife population dynamics in human-dominated landscapes under community-based conservation: The example of Nakuru Wildlife Conservancy, Kenya. PloS one, 12(1), e0169730. https://doi.org/10.1371/journal.pone.0169730

Okello, M. M. (2005). Land use changes and human-wildlife conflicts in the Amboseli Area, Kenya. Human Dimensions of Wildlife, 10(1), 19-28. https://doi.org/10.1080/10871200590904851

Omondi, P., Bitok, E., \& Kagiri, J. (2004). Managing human-elephant conflicts: the Kenyan experience. Pachyderm, 36, 80-86.

Opiyo, F. E., Mureithi, S. M., \& Ngugi, R. K. (2011). The Influence of Water Availability on Pastoralist's Resource Use in Mwingi and Kitui Districts in Kenya. Journal of Human Ecology, 35(1), 43-52.

Owen-Smith, R. N. (1992). Megaherbivores: the influence of very large body size on ecology. Cambridge University press. Cambridge

Packer, C., Loveridge, A., Canney, S., Caro, T., Garnett, S. T., Pfeifer, M., ... Balme, G. (2013). Conserving large carnivores: dollars and fence. Ecology Letters, 16(5), 635-641. https://doi.org/10.1111/ele.12091

Patterson, B. D. (2007). On the nature and significance of variability in lions (Panthera leo). Evolutionary Biology, 34(1-2), 55-60. https://doi.org/10.1007/s11692-007-9003-6

Patterson, B. D., Kasiki, S. M., Selempo, E., \& Kays, R. W. (2004). Livestock predation by lions (Panthera leo) and other carnivores on ranches neighboring Tsavo National Parks, Kenya. Biological Conservation, 119(4), 507-516. https://doi.org/10.1016/j.biocon.2004.01.013

Reed, D. D. H. (2012). Impact of Climate Change on Biodiversity. In W.-Y. Chen, J. Seiner, T. Suzuki, \& M. Lackner (Eds.), Handbook of Climate Change Mitigation (pp. 505-530). Springer US. https://doi.org/10. 1007/978-1-4419-7991-9_15

Reed, D. H. (2008). The effects of population size on population viability: from mutation to environmental catastrophes. Conservation Biology: Evaluation in Action. Oxford University Press, Oxford, 16-34.

Røskaft, E., Larsen, T., Mojaphoko, R., Raihan Sarker, A. H. M., \& Jackson, C. (2014). Human dimensions of elephant ecology. In C. Skarpe, J. T. du Toit, \& S. R. Moe (Eds.), Elephants and Savanna Woodland Ecosystems: A Study from Chobe National Park (pp. 269-288). https://doi.org/10.1002/97811188 58615.ch16

Sarker, A. R., \& Røskaft, E. (2014). Perceptions of farmers in Bangladesh to Asian Elephants (Elephas maximus) as an Agricultural Pest in. Environment and Natural Resources Research, 4(3), 23. http://dx.doi.org/10. 5539/enrr.v4n3p23

Sitati, N. W., Walpole, M. J., Smith, R. J., \& Leader-Williams, N. (2003). Predicting spatial aspects of human-elephant conflict. Journal of Applied Ecology, 40(4), 667-677. https://doi.org/10.1046/j.1365-2664. 2003.00828.x

Smith, R. J., \& Kasiki, S. (2000). A spatial analysis of human-elephant conflict in the Tsavo ecosystem, Kenya. IUCN/Species Survival Commission African Elephant Specialist Group, Human-Elephant Conflict Task Force, Gland, Switzerland. Retrieved from https://www.researchgate.net/profile/Robert_Smith33 /publication/265011932_A_Spatial_Analysis_of_Human-Elephant_Conflict_in_the_Tsavo_ Ecosystem_Kenya /links/54ae71570cf2828b29fd2c39.pdf

Mwiu, S., Kiambi, S., Bett, A., Mukeka, J., Nyaligu, M., Ikime, T., ...Maloba, M. (2017). Aerial total count of elephant, buffalo and giraffe in the mara ecosystem. Unpublished report. 
Strum, S. C. (1994). Prospects for management of primate pests. In Symposium" Les primates commensaux", tenu à Strasbourg, France, le 19 août 1994, à l'occasion du XIVe congrès de la Société internationale de Primatologie. Société nationale de protection de la nature et d'acclimatation de France, Paris (FRA).

Strum, S. C. (2010). The development of primate raiding: implications for management and conservation. International Journal of Primatology, 31(1), 133-156. https://doi.org/10.1007/s10764-009-9387-5

Thouless, C. R. (1994). Conflict between humans and elephants on private land in northern Kenya. Oryx, 28(02), 119-127. https://doi.org/10.1017/S0030605300028428

Tweheyo, M., Tumusiime, D. M., Turyahabwe, N., Asiimwe, A., \& Orikiriza, L. (2012). Wildlife damage and control methods around Lake Mburo National Park, Uganda. International Journal of Pest Management, 58(1), 25-31. https://doi.org/10.1080/09670874.2011.641605

Van Wijngaarden, W. (1985). Elephants-trees-grass-grazers. Relationships between Climate, Soils, Vegetation and Large Herbivores in a Semi-Arid Savanna Ecosystem (Tsavo, Kenya). ITC Publication, (4).

Wambua. (2017). Tsavo Ecoystem Conflict Mitigation: Fences, Functionality and Management Audit Report 2017. KWS. (Unpublished report)

Wildlife Works. (2013). REDD+resources page. Wildlife Works. Retrieved from http://www.wildlifeworks.com/ redd/resources.php

White, P. C., \& Ward, A. I. (2011). Interdisciplinary approaches for the management of existing and emerging human-wildlife conflicts. Wildlife Research, 37(8), 623-629. https://doi.org/10.1071/WR10191

Woodroffe, R., Hedges, S., \& Durant, S. M. (2014). To fence or not to fence. Science, 344(6179), 46-48. https://doi.org/10.1126/science.1246251

Woodroffe, R., Thirgood, S., \& Rabinowitz, A. (2005). The impact of human-wildlife conflict on natural systems. Conservation biology series-cambridge, 9, 1. https://doi.org/10.1017/CBO9780511614774.002

\section{Appendixes}

Table S5. The contributions of the common conflict types to outcomes involving threats to humans, human injuries or fatalities in the Tsavo and Mara regions

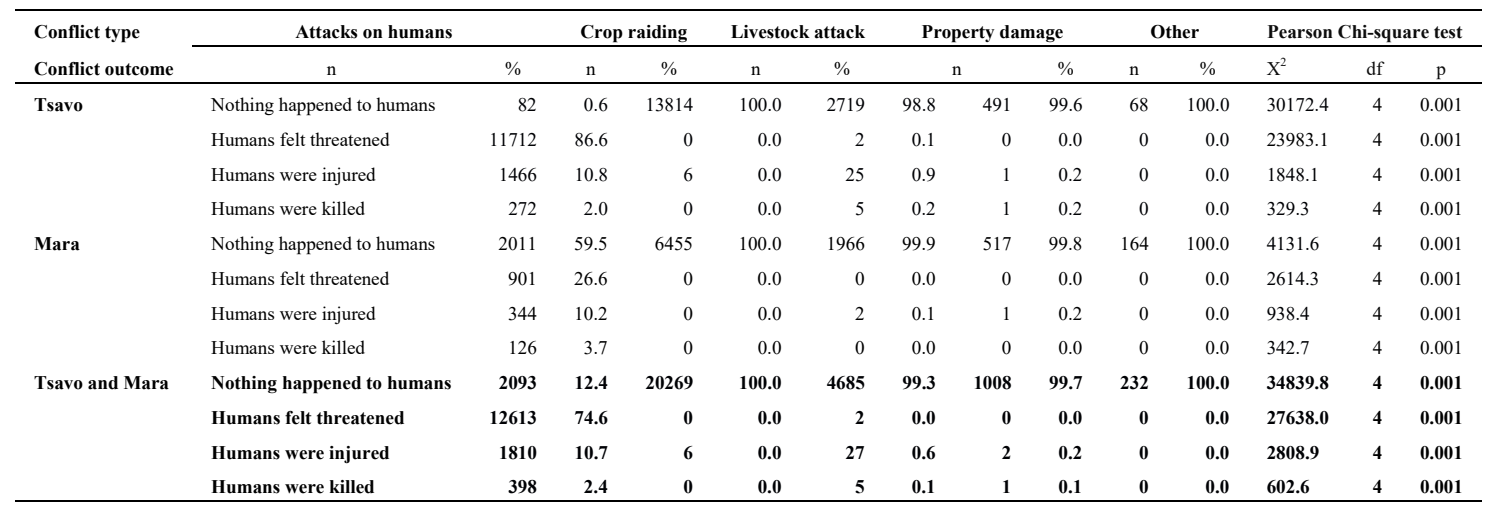

Table S6. Outcomes of conflicts involving livestock in the Tsavo and Mara regions (separately and pooled) and the contributions of the common conflict types to the outcomes

\begin{tabular}{|c|c|c|c|c|c|c|c|c|c|c|c|c|c|c|}
\hline & & \multicolumn{10}{|c|}{ Conflict type } & \multirow{2}{*}{\multicolumn{3}{|c|}{ Pearson Chi-square test }} \\
\hline & & \multicolumn{2}{|c|}{ Attack on humans } & \multicolumn{2}{|c|}{ Crop raiding } & \multicolumn{2}{|c|}{ Livestock attack } & \multicolumn{2}{|c|}{ Property damage } & \multicolumn{2}{|c|}{ Other } & & & \\
\hline & & $\mathrm{n}$ & $\%$ & $\mathrm{n}$ & $\%$ & $\mathrm{n}$ & $\%$ & $\mathrm{n}$ & $\%$ & $\mathrm{n}$ & $\%$ & $\mathrm{X} 2$ & $\mathrm{df}$ & $\mathrm{p}$ \\
\hline \multirow[t]{3}{*}{ Tsavo } & Nothing happened to livestock & 13482 & 99.6 & 13796 & 99.8 & 510 & 18.5 & 459 & 93.1 & 68 & 100.0 & 23300.3 & 4 & 0.001 \\
\hline & Livestock were injured & 0 & 0.0 & 5 & 0.0 & 4 & 0.1 & 0 & 0.0 & 0 & 0.0 & 17.0 & 4 & 0.002 \\
\hline & Livestock were killed & 50 & 0.4 & 19 & 0.1 & 2237 & 81.3 & 34 & 6.9 & 0 & 0.0 & 23309.4 & 4 & 0.001 \\
\hline \multirow[t]{3}{*}{ Mara } & Nothing happened to livestock & 3373 & 99.7 & 6453 & 100.0 & 1150 & 58.4 & 517 & 99.8 & 164 & 100.0 & 4590.7 & 4 & 0.001 \\
\hline & Livestock were injured & 1 & 0.0 & 1 & 0.0 & 257 & 13.1 & 1 & 0.2 & 0 & 0.0 & 1380.7 & 4 & 0.001 \\
\hline & Livestock were killed & 8 & 0.2 & 1 & 0.0 & 561 & 28.5 & 0 & 0.0 & 0 & 0.0 & 3074.1 & 4 & 0.001 \\
\hline \multirow[t]{3}{*}{ Mara and Tsavo } & Nothing happened to livestock & 16855 & 99.7 & 20249 & 99.9 & 1660 & 35.2 & 976 & 96.5 & 232 & 100.0 & 25646.0 & 4 & 0.001 \\
\hline & Livestock were injured & 1 & 0.0 & 6 & 0.0 & 261 & 5.5 & 1 & 0.1 & $\mathbf{0}$ & 0.0 & 2059.9 & 4 & 0.001 \\
\hline & Livestock were killed & 58 & 0.3 & 20 & 0.1 & 2798 & 59.3 & 34 & 3.4 & 0 & 0.0 & 23280.7 & 4 & 0.001 \\
\hline
\end{tabular}


Table S7. Seasonal variation in each conflict types for the Tsavo and Mara regions

\begin{tabular}{|c|c|c|c|c|c|c|c|c|c|c|c|c|c|c|c|c|c|}
\hline & & & \multicolumn{12}{|c|}{ Month } & \multicolumn{3}{|c|}{ Pearson Chi-Square test } \\
\hline & & & Jan & Feb & Mar & Apr & May & Jun & Jul & Aug & Sep & Oct & Nov & Dec & $\mathrm{X}^{2}$ & $\mathrm{df}$ & $\mathrm{P}<0.05$ \\
\hline \multirow[t]{10}{*}{ Tsavo } & Attack on humans & $\mathrm{n}$ & 1010 & 929 & 1080 & 1018 & 1180 & 1246 & 1437 & 1336 & 1117 & 1119 & 1041 & 1019 & & & \\
\hline & & $\%$ & 7.5 & 6.9 & 8.0 & 7.5 & 8.7 & 9.2 & 10.6 & 9.9 & 8.3 & 8.3 & 7.7 & 7.5 & 195.8 & 11 & 0.001 \\
\hline & Crop raiding & $\mathrm{n}$ & 1657 & 1095 & 996 & 992 & 1422 & 1442 & 1466 & 1067 & 948 & 928 & 856 & 951 & & & \\
\hline & & $\%$ & 12.0 & 7.9 & 7.2 & 7.2 & 10.3 & 10.4 & 10.6 & 7.7 & 6.9 & 6.7 & 6.2 & 6.9 & 350.6 & 11 & 0.001 \\
\hline & Livestock attack & $\mathrm{n}$ & 225 & 182 & 221 & 239 & 214 & 229 & 242 & 272 & 249 & 242 & 242 & 194 & & & \\
\hline & & $\%$ & 8.2 & 6.6 & 8.0 & 8.7 & 7.8 & 8.3 & 8.8 & 9.9 & 9.1 & 8.8 & 8.8 & 7.1 & 62.8 & 11 & 0.001 \\
\hline & Property damage & $\mathrm{n}$ & 32 & 26 & 26 & 29 & 20 & 46 & 66 & 67 & 76 & 63 & 26 & 16 & & & \\
\hline & & $\%$ & 6.5 & 5.3 & 5.3 & 5.9 & 4.1 & 9.3 & 13.4 & 13.6 & 15.4 & 12.8 & 5.3 & 3.2 & 110.6 & 11 & 0.001 \\
\hline & Other & $\mathrm{n}$ & 12 & 9 & 7 & 4 & 2 & 5 & 6 & 5 & 3 & 8 & 2 & 5 & & & \\
\hline & & $\%$ & 17.6 & 13.2 & 10.3 & 5.9 & 2.9 & 7.4 & 8.8 & 7.4 & 4.4 & 11.8 & 2.9 & 7.4 & 16.6 & 11 & 0.096 \\
\hline \multirow[t]{10}{*}{ Mara } & Attack on human & $\mathrm{n}$ & 348 & 352 & 311 & 192 & 273 & 209 & 304 & 282 & 258 & 318 & 250 & 284 & & & \\
\hline & & $\%$ & 10.3 & 10.4 & 9.2 & 5.7 & 8.1 & 6.2 & 9.0 & 8.3 & 7.6 & 9.4 & 7.4 & 8.4 & 474.5 & 11 & 0.001 \\
\hline & Crop raiding & $\mathrm{n}$ & 274 & 279 & 517 & 682 & 850 & 921 & 969 & 750 & 440 & 279 & 246 & 243 & & & \\
\hline & & $\%$ & 4.2 & 4.3 & 8.0 & 10.6 & 13.2 & 14.3 & 15.0 & 11.6 & 6.8 & 4.3 & 3.8 & 3.8 & 1070.9 & 11 & 0.001 \\
\hline & Livestock attack & $\mathrm{n}$ & 184 & 173 & 165 & 161 & 206 & 186 & 135 & 162 & 140 & 148 & 143 & 163 & & & \\
\hline & & $\%$ & 9.4 & 8.8 & 8.4 & 8.2 & 10.5 & 9.5 & 6.9 & 8.2 & 7.1 & 7.5 & 7.3 & 8.3 & 113.9 & 11 & 0.001 \\
\hline & Property damage & $\mathrm{n}$ & 40 & 49 & 30 & 17 & 28 & 18 & 28 & 36 & 54 & 72 & 92 & 54 & & & \\
\hline & & $\%$ & 7.7 & 9.5 & 5.8 & 3.3 & 5.4 & 3.5 & 5.4 & 6.9 & 10.4 & 13.9 & 17.8 & 10.4 & 281.2 & 11 & 0.001 \\
\hline & Other & $\mathrm{n}$ & 17 & 4 & 8 & 2 & 4 & 16 & 17 & 9 & 13 & 20 & 15 & 39 & & & \\
\hline & & $\%$ & 10.4 & 2.4 & 4.9 & 1.2 & 2.4 & 9.8 & 10.4 & 5.5 & 7.9 & 12.2 & 9.1 & 23.8 & 126.3 & 11 & 0.001 \\
\hline
\end{tabular}

\section{Copyrights}

Copyright for this article is retained by the author(s), with first publication rights granted to the journal.

This is an open-access article distributed under the terms and conditions of the Creative Commons Attribution license (http://creativecommons.org/licenses/by/4.0/). 